Supporting Information

\title{
Salt of Organosilicon Framework as a Novel Emulsifier for Various Water-Oil Biphasic Systems and a Catalyst for Dibromination of Olefins in an Aqueous Medium
}

Honghao Yu, Houbing Zou, Runwei Wang*, Zongtao Zhang and Shilun Qiu

State Key Laboratory of Inorganic Synthesis and Preparative Chemistry,College of Chemistry, Jilin University, 2699 Qianjin Street, Changchun, 130012, China.

E-mail: wrunw@hotmail.com.

Telephone: $+86-431-85168115$

Fax numbers: +86-431-85168115

\section{Experimental Section}

\section{Chemicals and reagents}

Aqueous ammonia $\left(\mathrm{NH}_{3} \cdot \mathrm{H}_{2} \mathrm{O}, 28 \%\right)$, anhydrous ethanol and cetyltrimethyl ammonium bromide (CTAB, 99.0\%) were obtained from Sinopharm Chemical Reagent Co. Ltd, Shanghai in China. 1-octene, cyclohexene, 2-Hexen-1-ol, cycloheptene, 2-butene-1,4diol, $\mathrm{NH}_{4} \mathrm{NO}_{3}$ and hydrogen bromide were purchased from TCI, Shanghai, China. Bromine, cyclopentene, ethyl acrylate and 2-octene were obtained from Beijing Chemical Works, Beijing, China. The chemical reagents used in this experiment were not further purified. Organosiloxane precursors 2,5-bis[ ( E ) -2(triethoxysilyl)vinyl]pyridine $\quad$ (BTOSVP) and 2,5-bis[(E)-2(triethoxysilyl)vinyl]benzene (BTOSVB) were synthesized according to the literature. 


\section{Synthesis of 2,5-Bis[(E)-2-(triethoxysilyl)vinyl]pyridine (Fig. S1)}

2,5-Bis(trimethylsilylethynyl)pyridine. A suspension of 2,5-diiodopyridine (10 g, $30.2 \mathrm{mmol}), \mathrm{PdCl}_{2}\left(\mathrm{PPh}_{3}\right)_{2}(0.85 \mathrm{~g}, 1.21 \mathrm{mmol})$ and $\mathrm{CuI}(0.12 \mathrm{~g}, 0.60 \mathrm{mmol})$ in $\mathrm{PPr}_{2} \mathrm{NH}$ $(120 \mathrm{ml})$ and THF $(40 \mathrm{ml})$ was cooled with an ice bath, and then to this suspension was added trimethylsilylacetylene (11.8 g, $121 \mathrm{mmol})$ under an argon atmosphere. The reaction mixture was stirred at room temperature for $16 \mathrm{~h}$. The resulting mixture was filtered to remove insoluble matter, and the filtrate was concentrated under reduced pressure. The residue was chromatographed on silica gel (hexane/AcOEt $=10: 1)$ to give 2,5-bis(trimethylsilylethynyl)pyridine (7.4 g, 90\%). ${ }^{1} \mathrm{H}$ NMR (400 MHz, CDCl3): $\delta$ $0.26(9 \mathrm{H}, \mathrm{s}), 0.27(9 \mathrm{H}, \mathrm{s}), 7.38(1 \mathrm{H}, \mathrm{d}, \mathrm{J}=8.24 \mathrm{~Hz}), 7.68(1 \mathrm{H}, \mathrm{dd}, 8.24 \mathrm{~Hz}), 8.62(1$ $\mathrm{H}, \mathrm{s}) ;{ }^{13} \mathrm{C}$ NMR (100MHz, CDCl3): $\delta-0.1,0.0,97.3,100.5,101.4,103.6,119.8,126.7$, 139.0, 141.9, 152.9. The ${ }^{1} \mathrm{H}$ and ${ }^{13} \mathrm{C}$ NMR data were identical to those reported in the literature.

2,5-Diethynylpyridine. To a THF $(160 \mathrm{~mL})$ solution of 2,5bis(trimethylsilylethynyl)pyridine $(7.4 \mathrm{~g}, 27.1 \mathrm{mmol})$ was added n-Bu4NF (1.0 M THF solution, $60 \mathrm{~mL}, 60 \mathrm{mmol}$ ) and a few drops of $\mathrm{H}_{2} \mathrm{O}$ subsequently. The reaction mixture was stirred for $4 \mathrm{~h}$ at room temperature, concentrated, and diluted with ether $/ \mathrm{H}_{2} \mathrm{O}$. The separated ether layer was washed with brine, dried over $\mathrm{MgSO}_{4}$, and then the solvent was completely evaporated. The residue was chromatographed on silica gel (hexane/AcOEt = 3:1) to give 2,5-diethynylpyridine (3.0 g, 88\%). ${ }^{1} \mathrm{H}$ NMR (400 MHz, CDCl3): $\delta 3.26(1 \mathrm{H}, \mathrm{s}), 3.31(1 \mathrm{H}, \mathrm{s}), 7.45(1 \mathrm{H}, \mathrm{dd}, \mathrm{J}=7.32 \mathrm{~Hz}), 7.75(1 \mathrm{H}, \mathrm{dd}, \mathrm{J}=$ 10.52 Hz), 8.68-8.69 (1 H, m); $\left.{ }^{13} \mathrm{C} \mathrm{NMR} \mathrm{(100} \mathrm{MHz,} \mathrm{CDCl}_{3}\right): \delta$ 79.1, 79.9, 82.3, 82.4, 
119.0, 126.7, 139.2, 141.5, 152.9. The ${ }^{1} \mathrm{H}$ and ${ }^{13} \mathrm{C}$ NMR data were identical to those reported in the literature.

2,5-Bis [(E)-2-(triethoxysilyl)vinyl] pyridine. To a $\mathrm{CH}_{3} \mathrm{CN}(27 \mathrm{~mL})$ solution of 2,5-diethynylpyridine (0.30 g, $2.36 \mathrm{mmol})$, [Rh(cod)Cl]2 $(23 \mathrm{mg}, 0.047 \mathrm{mmol}), \mathrm{PPh}_{3}$ (50 mg, 0.19mmol) was added triethoxysilane (1.55 g, $9.44 \mathrm{mmol})$ under an argon atmosphere. The reaction mixture was stirred at $100{ }^{\circ} \mathrm{C}$ for $24 \mathrm{~h}$. After cooling to room temperature, the reaction mixture was filtered through charcoal and Celite bed, and then the solvent was completely evaporated. The residue was purified by Kugelrohr distillation at $190-200{ }^{\circ} \mathrm{C} / 30 \mathrm{~Pa}$ to give 2,5 -Bis[(E)-2-(triethoxysilyl)vinyl]pyridine (Fig. S2) (0.47 g, 44\%) as a yellow oil. IR (neat): $v \max 2974,2928,2893,1603,1545$, 1477, 1439, 1389, 1078, $960 \mathrm{~cm}-1 ;{ }^{1} \mathrm{H}$ NMR $\left(\mathrm{CDCl}_{3}, 400 \mathrm{MHz}\right): \delta 1.25-1.29(18 \mathrm{H}$, m), 3.86-3.92 (12 H, m), 6.27 (1 H, d, J = 19.68 Hz),6.70 (1 H, d, J = 19.68 Hz), 7.19 $(1 \mathrm{H}, \mathrm{d}, \mathrm{J}=19.68 \mathrm{~Hz}), 7.28(1 \mathrm{H}, \mathrm{d}, \mathrm{J}=19.20 \mathrm{~Hz}), 7.40(1 \mathrm{H}, \mathrm{d}, \mathrm{J}=8.24 \mathrm{~Hz}) 7.77-7.79$ $(1 \mathrm{H}, \mathrm{m}), 8.64(1 \mathrm{H}, \mathrm{d}, \mathrm{J}=2.28 \mathrm{~Hz}) ;{ }^{13} \mathrm{C} \mathrm{NMR}(\mathrm{CDCl} 3,100 \mathrm{MHz}): \delta$ 18.2,58.7, 120.9, $121.7,123.3,132.4,133.5,145.0,147.9,148.9,155.1$

\section{Synthesis of 1,4-bis-((E)-2-(triethoxysilyl)vinyl)-benzene (Fig. S2)}

In a typical synthesis $30.12 \mathrm{~g}(0.128 \mathrm{~mol})$ of 1,4-dibromobenzene was dissolved in 220 $\mathrm{mL}$ of dimethylformamide in a $500 \mathrm{~mL}$ three-necked-flask. To this solution $55 \mathrm{~mL}$ $(0.261 \mathrm{~mol})$ of vinyltriethoxysilane, $70 \mathrm{~mL}(0.512 \mathrm{~mol})$ of triethylamine, and $0.493 \mathrm{~g}$ $(4.27 \times 10-4 \mathrm{~mol})$ of tetrakis(triphenylphosphine)-palladium were added. After the reaction mixture was stirred for $4 \mathrm{~d}$ at $110{ }^{\circ} \mathrm{C}$ under an argon atmosphere, the resulting solution was cooled to $0{ }^{\circ} \mathrm{C}$ to complete the precipitation of the formed salt (HNEt3Br). 
After removal of the salt by filtration, the solvent was removed under reduced pressure. The obtained raw product was purified by Kugelrohr distillation. For further purification of the precursor this distillation step was repeated twice: $41.7 \mathrm{~g}(0.092 \mathrm{~mol}$, yield: $71 \%$ ) of the organosilane precursor was obtained as a slightly yellow transparent liquid. ${ }^{1} \mathrm{H}$ NMR (400 MHz, CDCl $)$ ): $\delta 1.27$ (t, J ) 6.89 Hz, 18 H), 3.89 (q, J ) 6.89 Hz, 12 H), 6.19 (d,J ) 19.2 Hz, 2 H), 7.20 (d, J ) 19.2 Hz, 2 H), 7.46 (s, 4 H). ${ }^{13} \mathrm{C}$ NMR (100 $\mathrm{MHz}, \mathrm{CDCl} 3): \delta 18.2,58.5,118.2,126.9,137.9,148.3$.

\section{Dispersion process of SOF nanoparticles in water or organic solvents}

$10 \mathrm{mg}$ SOF nanoparticles were added into $5 \mathrm{ml}$ water, styrene, toluene, 1- octene and n-octane solution, respectively. After ultrasonic treatment for 5 minutes, the solution was placed for 3 hours before the phenomenon was observed.

\section{Adsorption of bromoethanol product / water}

At different temperatures $(288.15 \mathrm{~K}, 298.15 \mathrm{~K}, 308.15 \mathrm{~K}), 35 \mu \mathrm{L}$ bromoethanol product were added to $2 \mathrm{~mL}$ of water containing $100 \mathrm{mg}$ of SOF nanoparticles. The adsorptions were carried out in a sealed glass vial by equilibrating the mixture for $12 \mathrm{~h}$ on a magnetic stirring apparatus. After adsorption, the materials were directly removed from solution by filtration. The mass of SOF nanoparticles adsorbed bromoethanol product / water is $\mathrm{ml}$. The bromoethanol product in water was extracted by ethyl acetate for 3 times. Then, the amount of bromoethanol product in ethyl acetate was measured with an external standard method by gas chromatography. The bromoethanol product 
adsorption capacities of the SOF materials were calculated and recorded as $\mathrm{m} 2$. The water adsorption capacities of the SOF materials were recorded as $\mathrm{m} 3$ and calculated according to the equation of $\mathrm{m} 3=\mathrm{m} 1-100 \mathrm{mg}-\mathrm{m} 2$ (Fig. S6).

\section{Equilibrium Adsorption Isotherms}

Different amounts of bromoethanol/ dibromide products $(15 \mu \mathrm{L}, 25 \mu \mathrm{L}, 35 \mu \mathrm{L}, 45 \mu \mathrm{L}$ and $55 \mu \mathrm{L}$ ) were added to $5 \mathrm{~mL}$ of water containing $100 \mathrm{mg}$ of SOF at $288.15 \mathrm{~K}, 298.15$ $\mathrm{K}, 308.15 \mathrm{~K}$ and $318.15 \mathrm{~K}$, respectively. The adsorption was carried out in a sealed glass vial by equilibrating the mixture for $6 \mathrm{~h}$ on a magnetic stirring apparatus. After adsorption, the materials were directly removed from solution by filtration. The bromoethanol/ dibromide products in water were extracted by ethyl acetate for 3 times. Then, the amount of bromoethanol/ dibromide products in ethyl acetate was measured with an external standard method by gas chromatography.

To obtain the working curve of bromoethanol/ dibromide products in ethyl acetate, the different known bromoethanol/ dibromide products in ethyl acetate was measured under the same condition by gas chromatography. A well-fitted linear equation, A = $94.15 \cdot \mathrm{C}+6.01$, was obtained with a correlation coefficient $\left(\mathrm{R}^{2}\right)$ of 0.9998 , where $\mathrm{C}$ is the concentration of bromoethanol/ dibromide products in ethyl acetate, A is the peak area corresponding to different concentrations. The adsorption capacities of the materials were calculated according to the equation of $\mathrm{Qe}=\left(\mathrm{C}_{0}-\mathrm{Ce}\right) \mathrm{V} / \mathrm{m}$, where $\mathrm{C}_{0}$ and Ce represent the initial and equilibrium concentrations $\left(\mathrm{mg} \mathrm{g}^{-1}\right)$, where $\mathrm{V}$ is the volume of the solution $(\mathrm{mL})$, and $\mathrm{m}$ is the amount of the materials $(\mathrm{mg})$.

\section{Calculation of Adsorption Enthalpy}


$25 \mu \mathrm{L}$ of bromoethanol/ dibromide products were added to $4 \mathrm{~mL}$ of water containing $100 \mathrm{mg}$ of SOF at different temperatures $(288.15 \mathrm{~K}, 298.15 \mathrm{~K}, 308.15 \mathrm{~K}$ and 318.15 K). The processing steps were the same as above. The adsorption enthalpy was calculated following the derivative Clausius-Clapeyron equation ${ }^{1,2}$, $\ln \mathrm{Ce}=\Delta \mathrm{H} /(\mathrm{RT})+\ln \mathrm{K}$, where $\Delta \mathrm{H}$ is the adsorption enthalpy $(\mathrm{KJ} / \mathrm{mol}), \mathrm{T}$ is the absolute temperature $(\mathrm{K}), \mathrm{R}$ is the ideal gas constant $[8.314 \mathrm{~J} /(\mathrm{mol} \cdot \mathrm{K})]$, and $\mathrm{K}$ is a constant.

Addition reaction of olefins tests using porous structured Ethyl-PMO、Ph-PMO、

\section{Vinyl-Ph-PMO、Py-OF and SOF nanospheres}

We did controlled experiments using porous structured Ethyl-PMO、Ph-PMO、VinylPh-PMO、Py-OF and SOF nanoparticles. In a typical controlled experiment, molecular bromine (1.02 mmol), $100 \mathrm{mg}$ porous structured controlled nanoparticles and $4 \mathrm{~mL}$ of $\mathrm{H}_{2} \mathrm{O}$ were mixed in two $10 \mathrm{~mL}$ round-bottom flask equipped with a magnetic stirrer for $30 \mathrm{~min}$. Then $1.0 \mathrm{mmol}$ cyclohexene was added to the above reaction system with stirring for $90 \mathrm{~min}$. After completion of the reaction, the solid nanospheres were recovered by centrifugation and the product was extracted by ethyl acetate 3 times. The liquid phase was subsequently analyzed by using a gas chromatography-mass spectrum Shimadzu GCMS-QP2010 Plus with a flame ionization detector (FID), using dodecane as an internal standard. The column was GsBP-1 ms (30 m); the initial temperature was $50{ }^{\circ} \mathrm{C}$, the heating rate was $10{ }^{\circ} \mathrm{C} \min -1$, and the final temperature was $280{ }^{\circ} \mathrm{C}$, the temperature of the FID detector was $250{ }^{\circ} \mathrm{C}$. 

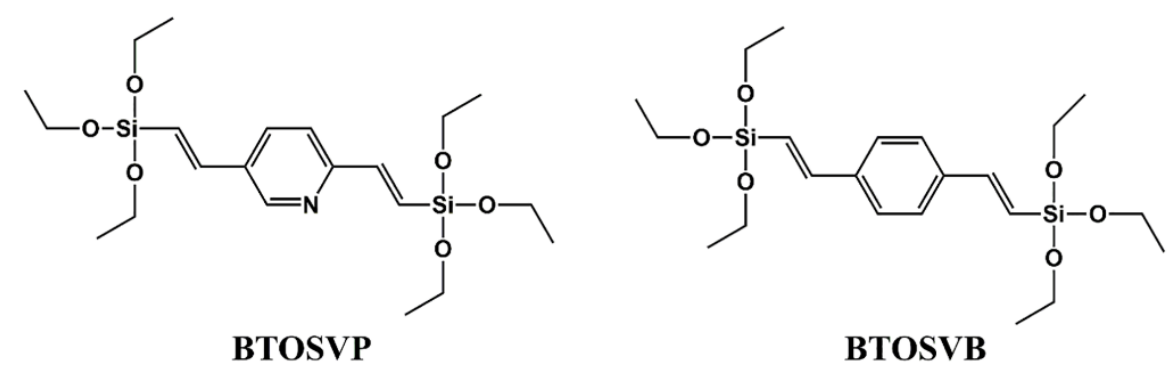

Figure S1. Structural formulas of 2,5-Bis[(E)-2-(triethoxysilyl)vinyl]pyridine (BTOSVP) and 1,4bis-((E)-2-(triethoxysilyl)vinyl)-benzene (BTOSVB).

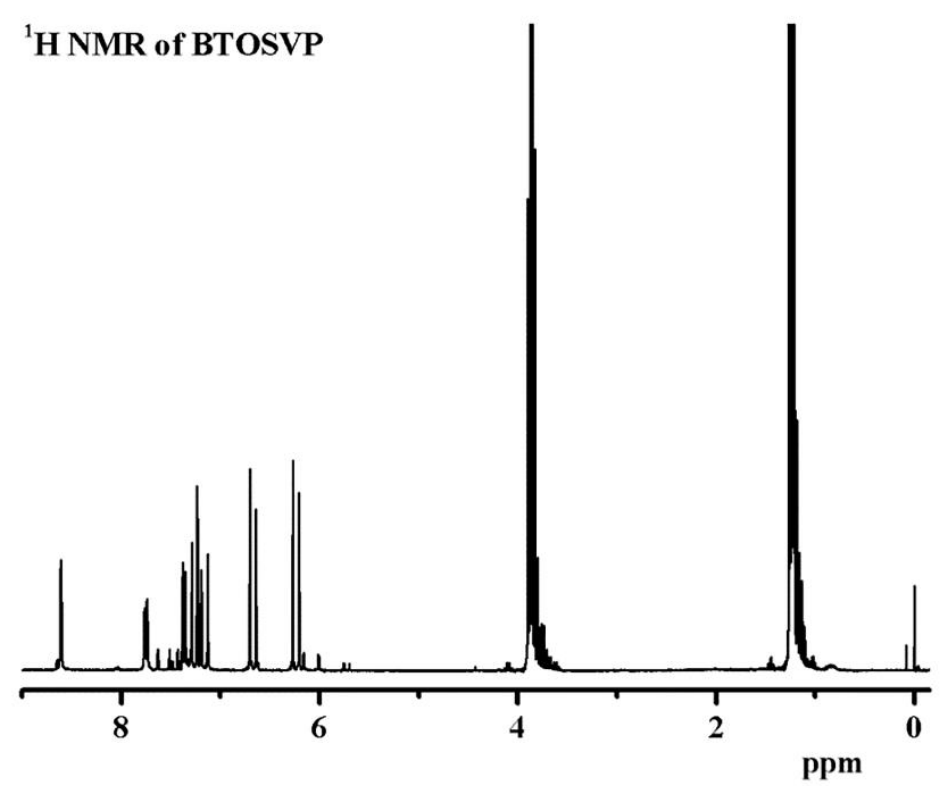

Figure S2. ${ }^{1} \mathrm{H}$ NMR spectras of 2,5-bis[(E)-2-(triethoxysilyl)vinyl]pyridine. 


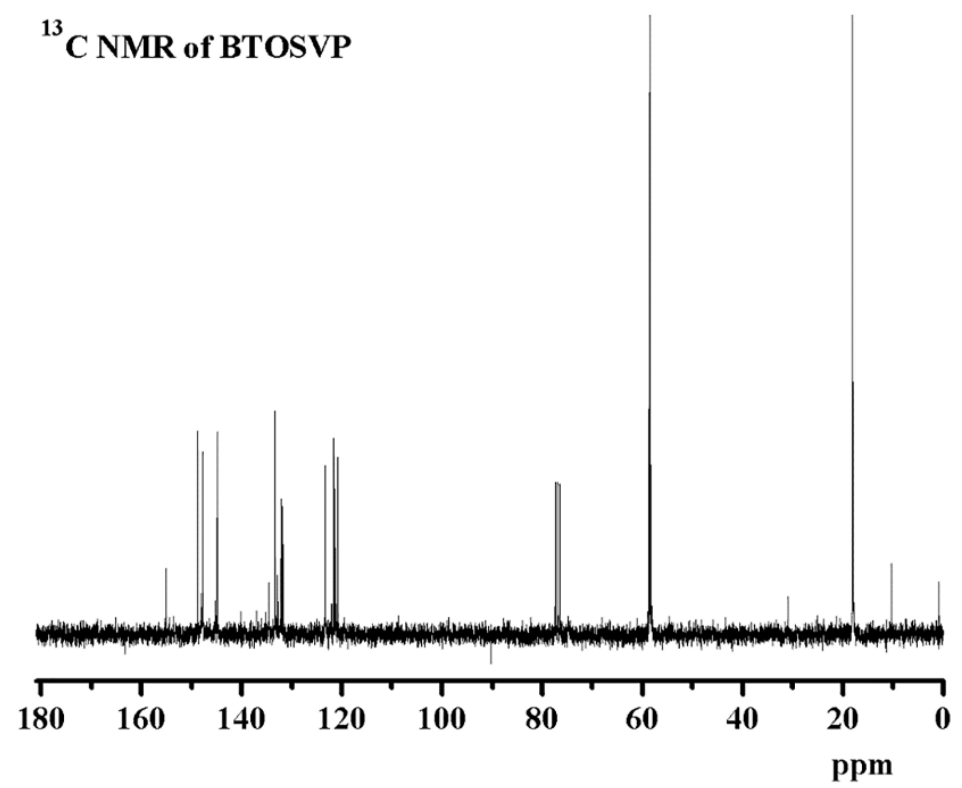

Figure S3. ${ }^{13} \mathrm{C}$ NMR spectras of 2,5-bis[(E)-2-(triethoxysilyl)vinyl]pyridine.

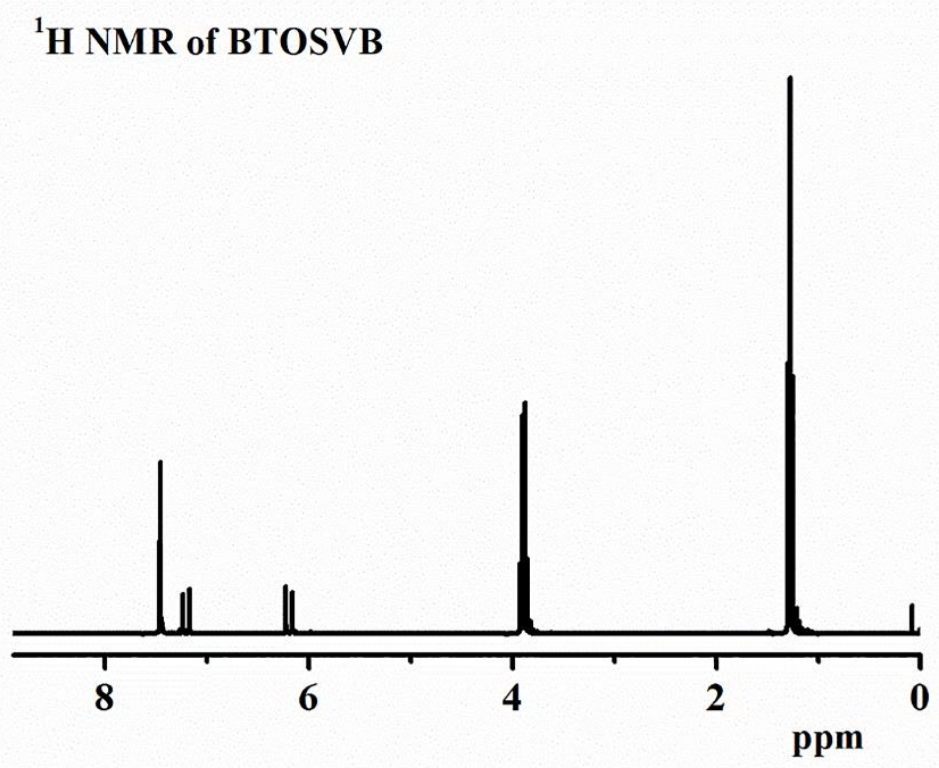

Figure S4. ${ }^{1} \mathrm{H}$ NMR spectras of 1,4-bis-((E)-2-(triethoxysilyl)vinyl)-benzene. 


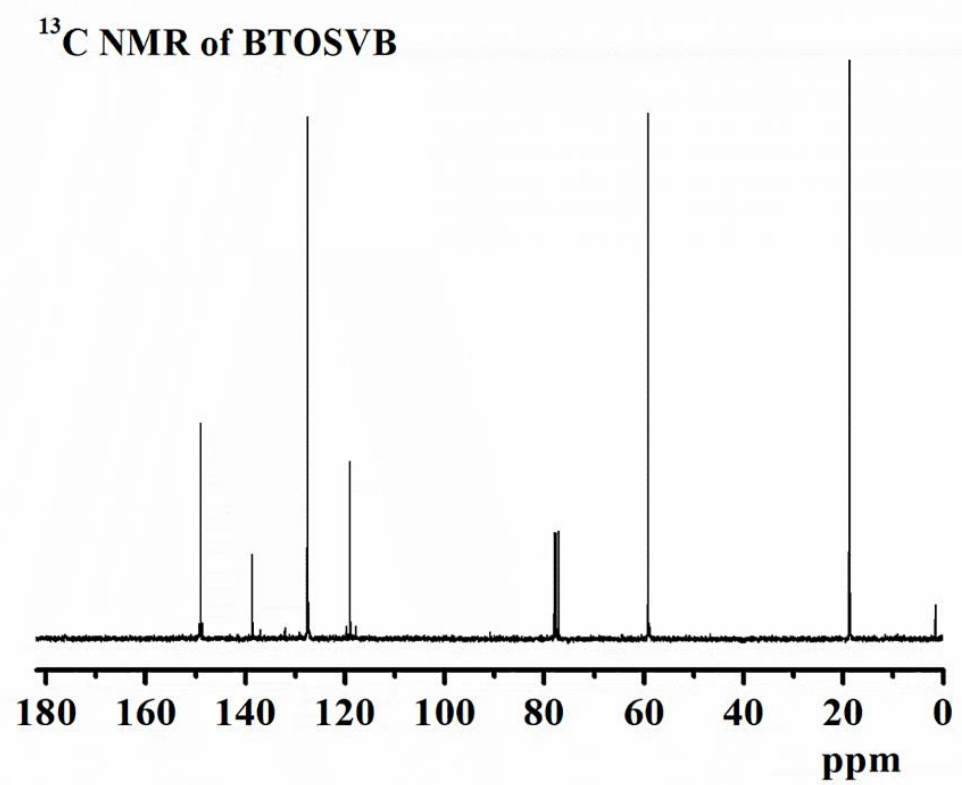

Figure S5. ${ }^{13} \mathrm{C}$ NMR spectras of 1,4-bis-((E)-2-(triethoxysilyl)vinyl)-benzene.
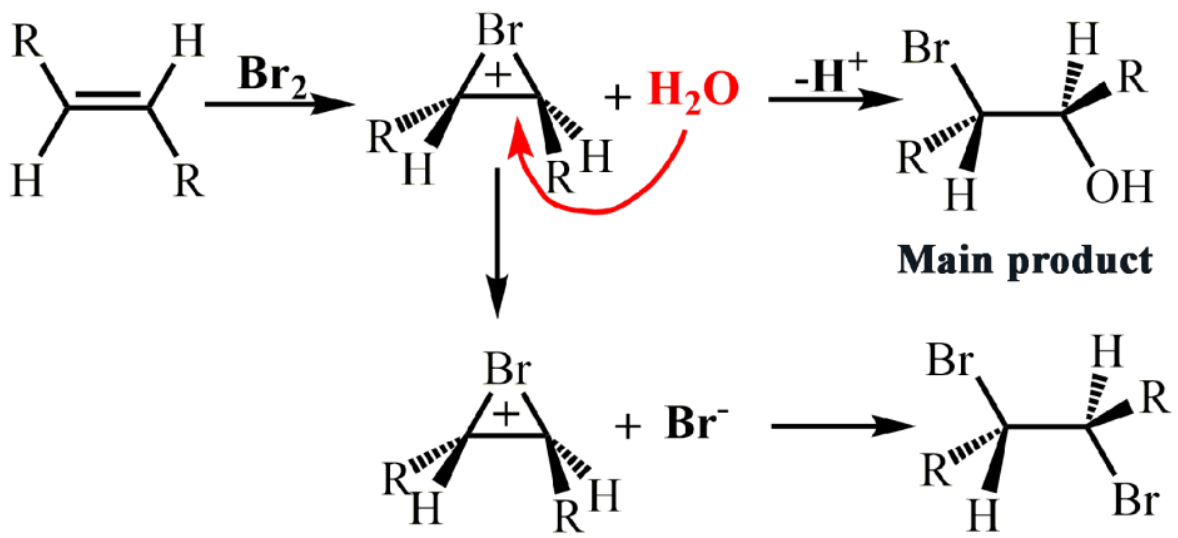

Figure S6. The electrophilic addition mechanism of controlled materials. 


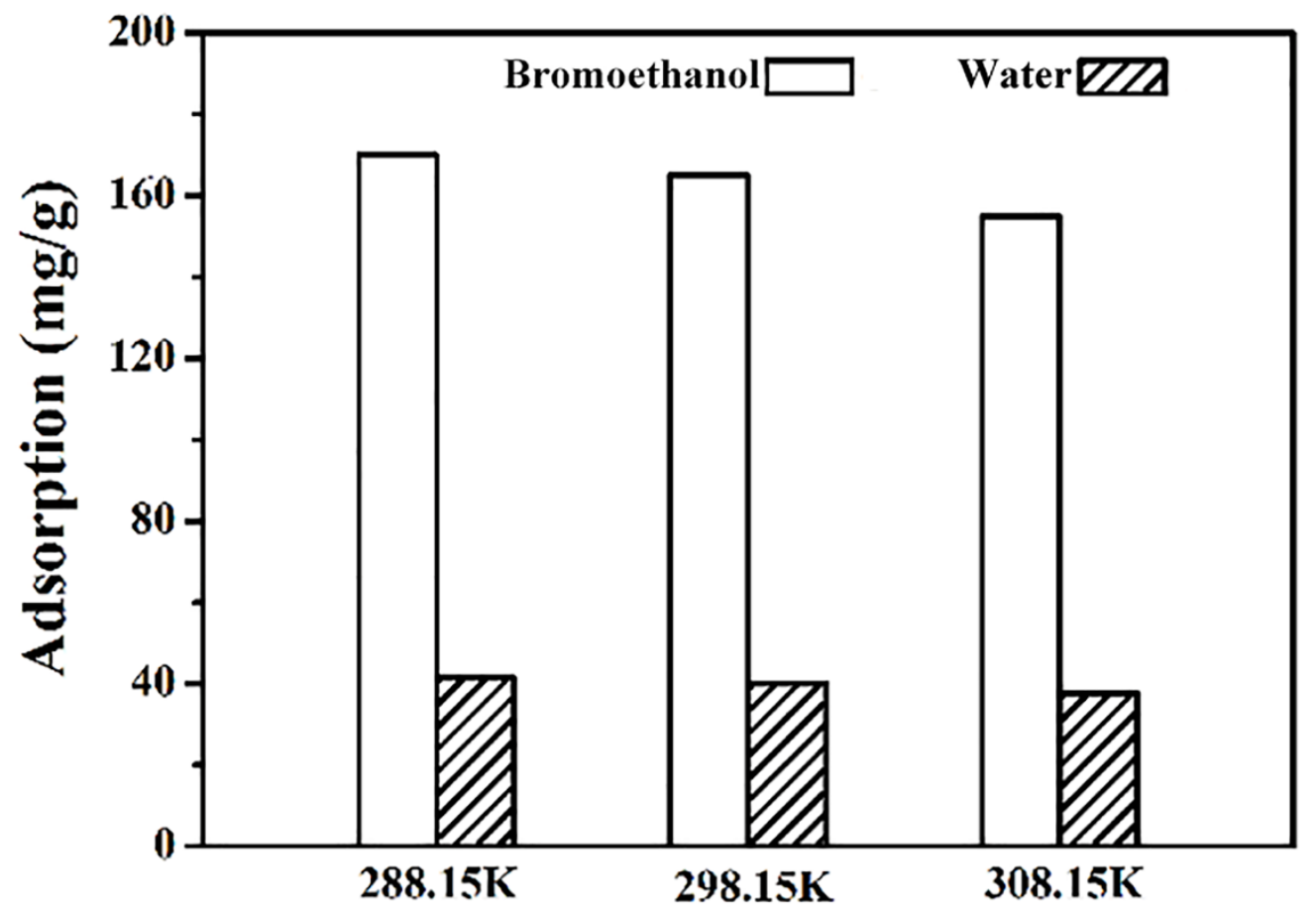

Figure S7. Uptakes of bromoethanol product/water under PIC condition from $288.15 \mathrm{~K}$ to $308.15 \mathrm{~K}$.
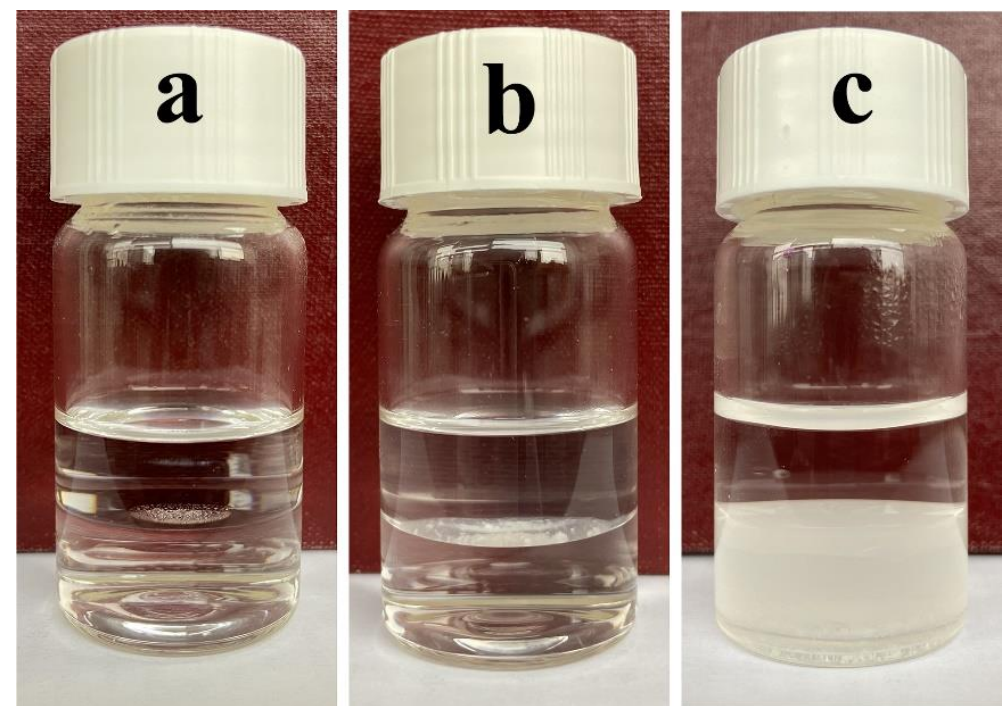

Figure S8. The CTAB, SOF and V-Ph-PMO were added to the above system lightly without shaking and ultrasonic, and the CTAB (a) and SOF (b) will eventually be at the interface of oil-water two phases, however, the V-Ph-PMO (c) has a little precipitation at the bottom of the sample bottle. 


\begin{tabular}{l|l|l|c}
\hline State & Type & Emulsifier & $\begin{array}{c}\text { Diameter } \\
(\mu \mathrm{m})\end{array}$ \\
\hline \multirow{2}{*}{ Non-solid } & Molecule & Ugi-Alg-CD/Azo-PEG & $5 \sim 50$ \\
\hline \multirow{4}{*}{ Solid } & \multirow{2}{*}{ Polymer } & SOF & $20 \sim 60$ \\
\cline { 3 - 4 } & \multirow{3}{*}{ Grafting } & Polyaniline nanofibers & 200 \\
\cline { 3 - 4 } & & Cn-SiO 2 -TMG & $70 \sim 172$ \\
\cline { 3 - 4 } & \multirow{3}{*}{ Adjusting ratios } & Janus CPSAA-PS & $37 \sim 65$ \\
\cline { 3 - 4 } & & Janus Carbon@Silica & $100 \sim 820$ \\
\hline
\end{tabular}

Figure S9. The emulsification droplet diameters formed by SOF nanoparticles and control material in reported researches.

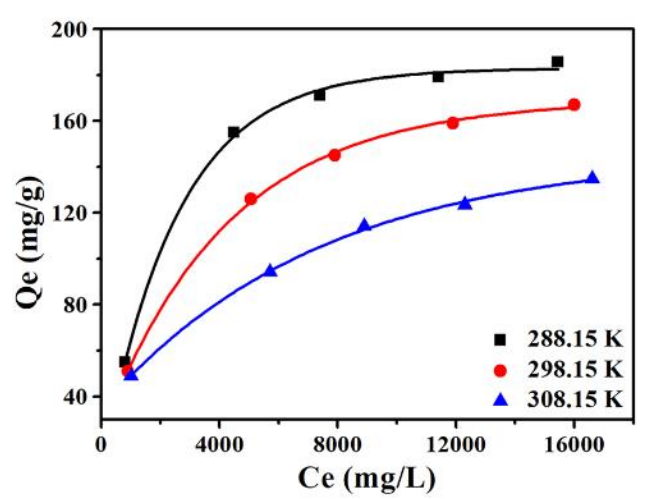

(a)

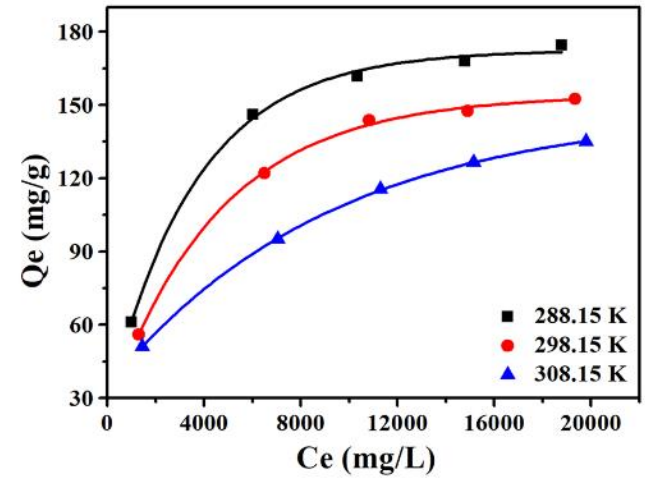

(b)

Figure S10. Adsorption Isotherms of trans-2-bromocyclohexanol (a) and trans-1,2dibromocyclohexane (b) on the sample mesoporous SOF spheres. 

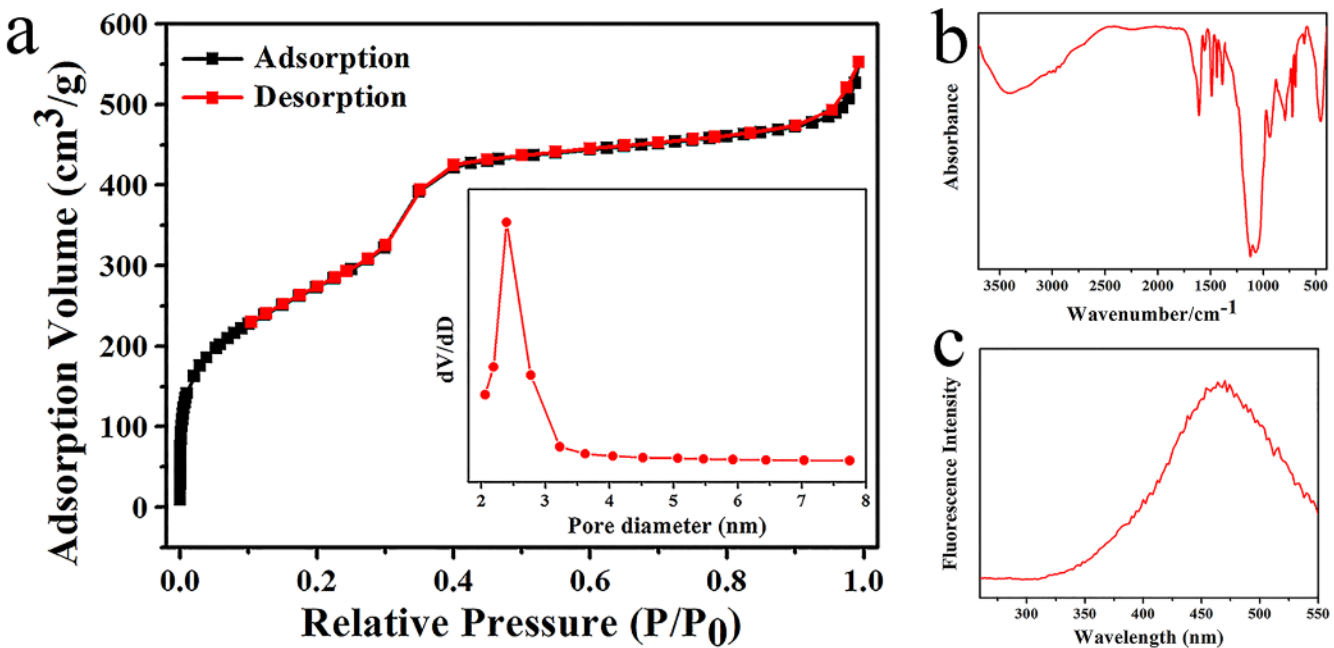

Figure S11. (a) Nitrogen adsorption-desorption isotherms (b) FT-IR spectra and (c) Fluorescence absorption of recovered SOF nanospheres after being reused eight times.

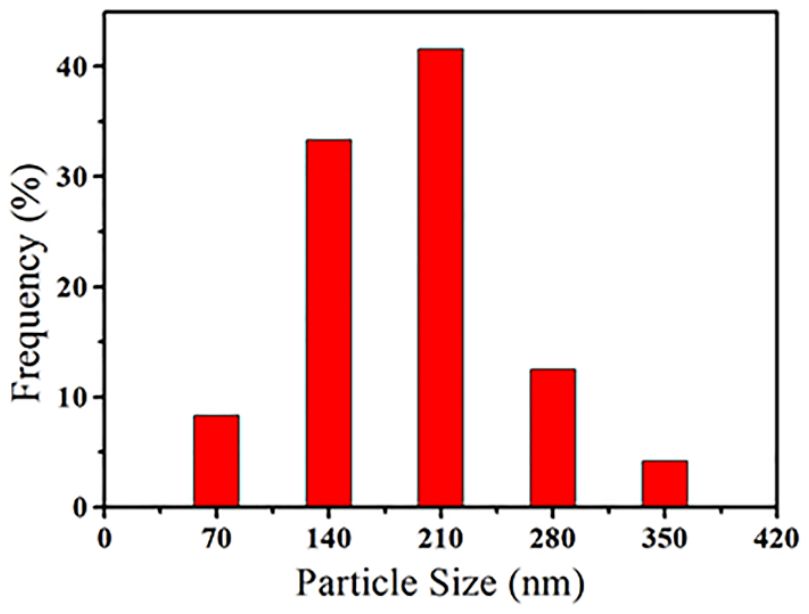

Figure S12. Particle size distribution of SOF nanoparticles. 


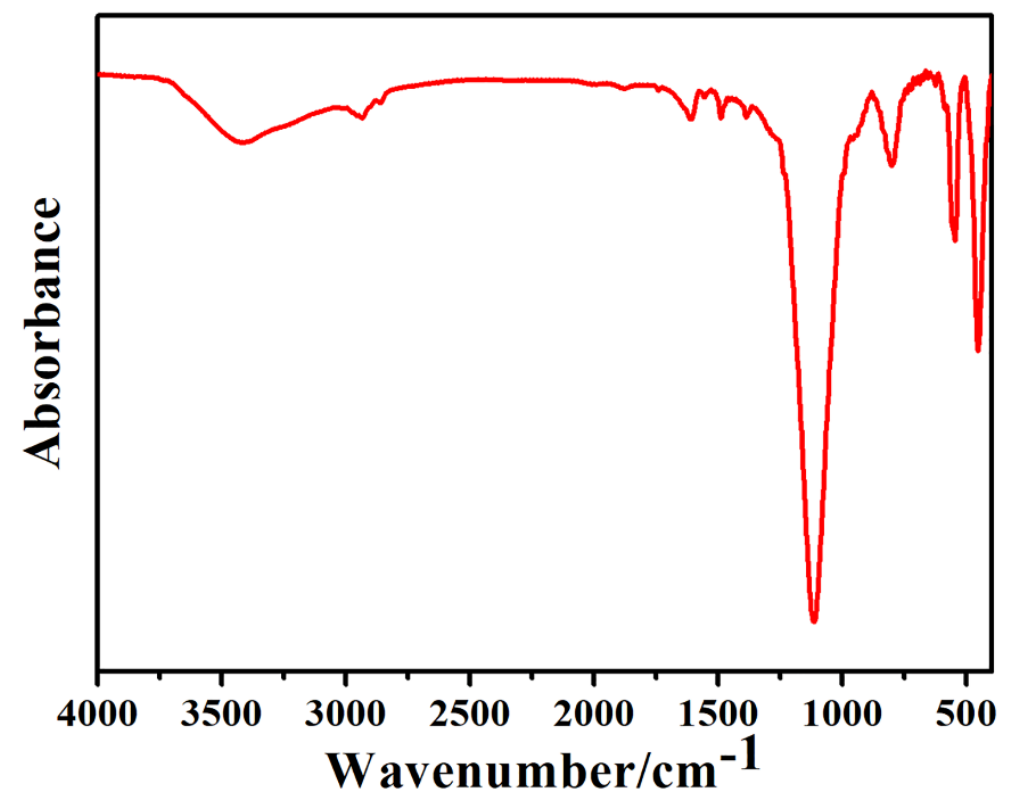

Figure S13. FT-IR spectra of the control sample V-Ph-PMO.

\section{${ }^{1} \mathrm{H}$ NMR and ${ }^{13} \mathrm{C}$ NMR of the Products Obtained in This Article}

1,2-Dibromooctane (Table 2, entry 1). ${ }^{1} \mathrm{H}$ NMR (270MHz, CDCl3)4 $\delta$ 0.86-0.92 $(\mathrm{m}, 3 \mathrm{H}), 1.301 .59(\mathrm{~m}, 8 \mathrm{H}), 1.75-1.85(\mathrm{~m}, 1 \mathrm{H}), 2.07-2.16(\mathrm{~m}, 1 \mathrm{H}), 3.63(\mathrm{t}, 1 \mathrm{H}, \mathrm{J}=$ $10 \mathrm{~Hz}), 3.85(\mathrm{dd}, 1 \mathrm{H}, \mathrm{J}=10,4.6 \mathrm{~Hz}), 4.12-4.22(\mathrm{~m}, 1 \mathrm{H}) ;{ }^{13} \mathrm{C} \mathrm{NMR}(67.5 \mathrm{MHz}, \mathrm{CDCl} 3) 5$ $\delta 14.01,22.56,26.27,28.49,31.57,35.96,36.24,52.95$; IR (neat) 2910, 2850, 1460, $1140,900,730 \mathrm{~cm}^{-1}$.

2, 3-Dibromooctane (Table 2, entry 2). ${ }^{1} \mathrm{H}$ NMR $(500 \mathrm{MHz}, \mathrm{CDCl} 3) \delta 0.91$ (t, 3.0H, $\mathrm{J}=6.87 \mathrm{~Hz}), 1.24-1.50(\mathrm{~m}, 5.0 \mathrm{H}), 1.56-1.66(\mathrm{~m}, 1.0 \mathrm{H}), 1.86(\mathrm{~d}, 2.8 \mathrm{H}, \mathrm{J}=6.87 \mathrm{~Hz})$, $1.90(\mathrm{~m}, 1.0 \mathrm{H}), 2.1(\mathrm{~m}, 1.0 \mathrm{H}), 4.08-4.14(\mathrm{~m}, 0.93 \mathrm{H}), 4.20-4.28(\mathrm{~m}, 1.0 \mathrm{H}) ;{ }^{13} \mathrm{C}$ NMR (125 MHz, CDCl3) $\delta 13.96,21.47,22.40,25.01,26.59,27.41,30.98,33.80,37.05$, 52.31, 61.62; IR (neat) a mixture of two diastereomers; 2930, 2860, 1452, 1380, $1320,1271,1199,1153,987,877,847,762,729 \mathrm{~cm}^{-1}$.

trans-1,2-Dibromocyclopentane (Table 2, entry 3). ${ }^{1} \mathrm{H} \mathrm{NMR}(270 \mathrm{MHz}, \mathrm{CDCl} 3) 3$ 
$\delta$ 1.95-2.06 (m, 2H), 2.11-2.22 (m, 2H), 2.59-2.73 (m, 2H), 4.57-4.60 (m, $2 \mathrm{H}) ;{ }^{13} \mathrm{C}$

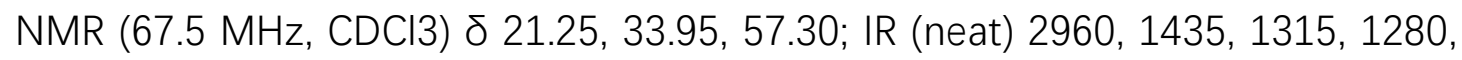
$1160,1125,885 \mathrm{~cm}^{-1}$.

trans-1,2-Dibromocyclohexane (Table 2, entry 4). ${ }^{1} \mathrm{H} \mathrm{NMR}(270 \mathrm{MHz}, \mathrm{CDCl}) 1$ $\delta$ 1.49-1.53 (m, 2H), 1.78-1.92 (m, 4H), 2.41-2.50 (m, 2H), $4.52(\mathrm{~s}, 2 \mathrm{H}) ;{ }^{13} \mathrm{C} N M R$

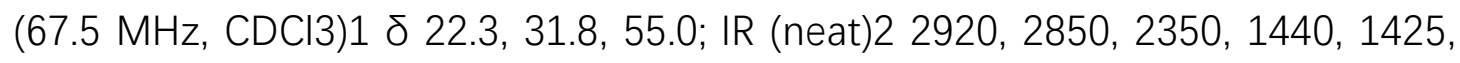
$1360,1335,1260,1175,990,960,900,860,800,730 \mathrm{~cm}^{-1}$.

trans-1,2-Dibromocycloheptane (Table 2, entry 5). ${ }^{1} \mathrm{H} \mathrm{NMR}\left(270 \mathrm{MHz}, \mathrm{CDCl}_{3}\right) \delta$ 1.56-1.72 (m, 4H), 1.80-1.92 (m, 2H), 2.00-2.12(m, 2H), 2.30-2.40 (m, 2H), 4.64$4.69(\mathrm{~m}, 2 \mathrm{H}) ;{ }^{13} \mathrm{C}$ NMR $\left(67.5 \mathrm{MHz}, \mathrm{CDCl}_{3}\right) \delta 23.24,26.52,33.21,60.13$; IR (neat) 2920, 2850, 2350, 1448, 1360, 1210, 1160, 1115, 1000, 908, 820, 740, $700 \mathrm{~cm}^{-1}$.

2,3-Dibromo-hexane-1-ol (Table 2, entry 6): ${ }^{1} \mathrm{H}$ NMR $\left(400 \mathrm{MHz}, \mathrm{CDCl}_{3}\right): \mathrm{d}=$ $0.96(t, 3 H), 1.48(m, 1 H), 1.65(m, 1 H), 1.92(m, 1 H), 2.15(m, 2 H), 4.11(m, 2 H), 4.30$ $(\mathrm{m}, 2 \mathrm{H}) .{ }^{13} \mathrm{C}$ NMR $\left(100 \mathrm{MHz}, \mathrm{CDCl}_{3}\right): \quad \mathrm{d}=13.8,20.4,39.3,55.2,60.8,66.3 . \mathrm{IR}$ : $3412,2968,2873,1462,1383,1158,1088,1053,749,555 \mathrm{~cm}^{-1}$.

2,3-Dibromo-butane-1,4-diol (Table 2, entry 7): ${ }^{1} \mathrm{H}$ NMR (400 $\mathrm{MHz}, \mathrm{CDCl}_{3}$ ): $\mathrm{d}=3.41$ (brs, 2H), $3.88(\mathrm{~m}, 2 \mathrm{H}), 3.99(\mathrm{~m}, 2 \mathrm{H}), 4.47(\mathrm{t}, J=4.8 \mathrm{~Hz}, 2 \mathrm{H}) \cdot{ }^{13} \mathrm{C} N M R(100$ $\left.\mathrm{MHz}, \mathrm{CDCl}_{3}\right): \quad \mathrm{d}=55.6,64.8 . \quad$ IR: 3273, 2950, 2868, 1450, 1368, 1230, 1081 , $1030,1014,942,742,691,640 \mathrm{~cm}^{-1}$. 